\title{
Metodologias ativas na formação continuada de professores de Física: os discursos dos professores
}

\author{
Active methodologies in the continuing education of Physics teachers: teachers' speeches \\ Metodologías activas en la formación continua del profesorado de Física: discurso del profesorado
}

Recebido: 30/08/2021 | Revisado: 07/09/2021 | Aceito: 09/09/2021 | Publicado: 12/09/2021

\author{
André Dias Martins \\ ORCID: https://orcid.org/0000-0001-7862-3468 \\ Universidade Estadual de Maringá, Brasil \\ E-mail: andredias.uem@gmail.com \\ Michel Corci Batista \\ ORCID: https://orcid.org/0000-0001-7328-2721 \\ Universidade Estadual de Maringá, Brasil \\ E-mail: profcorci@gmail.com \\ Ricardo Francisco Pereira \\ ORCID: https://orcid.org/0000-0001-7540-6601 \\ Universidade Estadual de Maringá, Brasil \\ E-mail: ricardoastronomo@gmail.com
}

\begin{abstract}
Resumo
O presente trabalho objetiva-se em analisar todo processo de mudanças no discurso de um grupo de professores de física participantes de um curso de formação continuada, vinculados ao Núcleo Regional de Educação (NRE) do município de Maringá. Após a análise dos dados, evidenciou-se três importantes fases oriundas do comportamento desse grupo de professores: a primeira, marcada por situações de queixas pelo fato do descrédito em relação a educação e aos muitos desafios enfrentados no cotidiano escolar, a segunda diretamente ligada às práticas metodológicas equivocadas assumidas em sala de aula, e a terceira por uma mudança de postura mais reflexivo. Para análise dos dados utilizou-se das metodologias oriundas dos pressupostos teóricos e metodológicos de Bardin, baseado na Análise de Conteúdo, cujo pesquisadores delimitam alguns parâmetros e categorias, demonstrando todo conhecimento por parte do aprendiz. Diante de tais práticas, conclui-se que somente será possível uma mudança no discurso da queixa ao discurso reflexivo quando o professor efetivamente convencer-se da necessidade de constantes aperfeiçoamentos, bem como o resgate por sua autoridade muitas vezes perdida em sala de aula.
\end{abstract}

Palavras-chave: Metodologias ativas; Formação continuada de professores; Ensino de Ciências.

\begin{abstract}
The aim of this article is to analyze the whole process of changes in the speech of a group of physics teachers who participate in a continued training course. This course belongs to the Regional Education Center (NRE) in the city of Maringá, Brazil. After data analysis, we evidenced three important phases of the behavior of this group of teachers. The first phase is marked by situations of complaints due to the fact of discredit in relation to education and the many challenges faced in daily school life. The second is directed to the wrong methodological practices assumed in the classroom. Finally, the third is a more reflective change of posture. For data analysis, we used the methodologies of Bardin's theoretical and methodological concepts, based on Content Analysis that delimits some parameters and categories. In this theoretical-methodological framework, whole knowledge can be demonstrated by the learner. In view of such practices, we conclude that it will only be possible to change the complaint speech to reflexive speech when the teacher effectively convinces himself of the need for constant improvements and rescue by his authority often lost in the classroom.
\end{abstract}

Keywords: Active methodologies; Teacher training; Science teaching.

\section{Resumen}

El objetivo de este artículo es analizar todo el proceso de cambios en el discurso de un grupo de profesores de física que participan en un curso de formación continua. Este curso está vinculado al Núcleo Regional de Educación (NRE) del municipio de Maringá. Después del análisis de datos, evidenciamos tres fases importantes del comportamiento de este grupo profesores. La primera fase está marcada por situaciones de quejas debido al hecho de descrédito en relación con la educación y muchos desafíos que se enfrenta la vida escolar diaria. Lo segundo está vinculado a las prácticas metodológicas equivocadas asumidas en el aula. La tercera fase es para un cambio de postura más reflexivo. Para el análisis de datos, utilizamos los presupuestos teóricos y metodológicos de Bardin, basadas en el Análisis de 
Contenido que delimita algunos parámetros y categorías. En este marco teórico-metodológico, todos los conocimientos pueden ser demostrados por el aprendiz. En vista de tales prácticas, llegamos a la conclusión de que sólo será posible cambiar el discurso de la queja al discurso reflexivo cuando el profesor se convence efectivamente de la necesidad de mejoras constantes y rescate por su autoridad muchas veces perdido en el aula.

Palabras clave: Metodologías activas; Formación continua de los profesores; Enseñanza de ciencias.

\section{Introdução}

Caracteriza-se como formação de professores, toda ação em que seja possível mudanças nas práticas pedagógicas durante todo percurso educacional e formativo dos alunos diretamente evolvidos nesse contexto. Segundo Nesi et al (2021), é fato que estes profissionais são os principais responsáveis por esta prática, são eles que possuem a importante missão da mediação e da construção do saber, visando com isso a evolução de todo conhecimento, do ensino aprendizagem.

Segundo a teoria de vários autores, entre eles, Berbel (2011), afirma que é na prática que todo processo formativo se torna efetivos. Há uma urgência dos professores em formação analisarem suas próprias práticas educacionais, bem como suas ações metodológicas utilizadas em suas aulas no dia a dia.

O referido autor ainda enfatiza que:

O docente é aquele que necessita ser um investigador nato, ao pesquisar suas práticas pedagógicas, analisar os dados coletados e repensar sobre eles. Algumas atribuições principais de um docente investigador são: compromissos, espírito colaborativo, intenção, observador e questionador, a partir daquilo que se analisa, realiza ou se ouve. (Berbel, 2011, p. 2).

Diante de tais realidades, e conforme o professor avança em suas práticas docentes, conquistando conhecimentos e saberes experenciados necessários para o exercício de sua profissão, ele coloca em prática todo um conjunto de saberes e ações oriundos de tudo aquilo que vivencia no dia a dia profissional e pessoal. Ou seja, o mesmo constrói, descontrói e/ou reconstrói suas práticas e identidade profissional docente, ora pautados por suas experiências pessoais, ora pelo acúmulo de conhecimentos conquistados ao longo de toda sua trajetória profissional.

\section{Formação de Professores}

Toda ação em que seja possível mudanças nas práticas pedagógicas durante todo percurso educacional e formativo dos alunos diretamente evolvidos nesse contexto é caracterizado como formação de professores.

O conhecimento adquirido pelo professor ao longo de sua caminhada quer seja na formação continuada, ou em sua formação inicial, permite que o mesmo vá aos poucos galgando por um processo de personificação profissional ou seja, é possível que o docente construa ou descontrua seu perfil profissional, isto acontece na medida em que se adquire as aptidões necessárias por sua trajetória docente.

Diante de todo este contexto, neste trabalho será explicitado algumas importantes considerações acerca da formação de professores de física, bem como a construção de sua identidade profissional docente para atualização e/ou formação destes profissionais.

Segundo afirmações de Nóvoa (1992), os professores de Física, além das urgentes necessidades de uma formação sólida e eficaz, também estão muito aquém de entender suas próprias exiguidades frente ao ensino aprendizagem. Pelo fato de estarem alheios a estas lacunas, os mesmos não compreendem a importância de uma constante formação acadêmica após sua graduação inicial.

O ensino é parte de todo processo didático, que segundo Silveira (2020, p. 14), compreende todo mecanismo de indicar os caminhos para o ensino aprendizagem e construir oportunidades que leva aluno a percorrer caminhos por ele construído. É fato que a construção da aprendizagem é uma via de mão dupla, onde o professor indaga, questiona, motiva e 
consequentemente leva o aluno a confiar nos comandos ditados pelo docente, bem como o aluno à partir destes comandos, busca sua melhor forma de aquisição pelo conhecimento.

Diante de tais práticas, Tardif (2000):

Optar pelo conhecimento supõe ir construindo-o dia após dia, com um certo rigor e um nível de exigência no que tange todo planejamento didático, pois toda busca pelo conhecimento nasce via atividades investigativas planejadas. É papel do professor a demanda de articular o ensino de uma forma que a torne participativa por todos os alunos envolvidos nesse processo. Há uma complexidade no que se refere ao ensino, pois trata-se de uma tarefa humana, com desafios e obstáculos de caráter afetivo e emocional. Diante disso, toda busca por esta interação deve estar totalmente voltada para os alunos no que diz respeito aos objetivos e conteúdos pertinentes a sala de aula propriamente dito (Tardif, 2000, p. 25).

\section{Professor Reflexivo}

Ao ser introduzido uma teoria acerca do Professor Reflexivo, esbarra-se em grandes críticas quanto ao raciocínio técnico, enfatizando sua falta de habilidade ao lidar com tudo aquilo que é inesperado, uma vez que tal postura contradiz as realidades vividas em um mundo real, limitando todo saber prático do professor, pelo saber técnico ou ainda pelo saber mecanizado.

Segundo as afirmações de Dewey (1959), a existência de três importantes tipos de pensamento, a saber: "corrente da consciência" ou "fantasia", o pensamento de crença e o pensamento reflexivo. O autor trata de "corrente da consciência" ou "fantasia" as formas confusas de se articularem as ideias presentes na cabeça do ser humano, de forma aleatória quando o sujeito se encontra acordado ou ainda dormindo em um determinado nível de sono.

Segundo o autor, inexiste a possibilidade de reflexão, quando se permite que as ações mentais, passe com sua neutralidade, de um determinado assunto a outro, ou ainda que os devaneios estejam diretamente ligados aos caprichos pessoais". (Dewey, 1959, p. 23).

Aquilo que o sujeito acredita, é uma outra forma de pensamento apresentado por Dewey (1959). Para o autor, a crença está enraizada em todas as situações que o sujeito não possui total conhecimento, ou ainda todas as propriedades necessárias para defender tais ideias. Porém, confia-se o suficiente para que seja depositado todas as ações e práticas do seu cotidiano (Dewey, 1959, p. 16).

Ele também enfatiza e defende a ideia de que o sujeito acredita na sua crença pessoal, descende de uma tradição na maioria das vezes oriunda de heranças familiares, onde toda essa maneira de pensar firma-se em prejulgamento e não em conclusões resultantes de uma ação mental sistemática e rigorosa.

Ainda segundo Dewey (1959), todo pensamento reflexivo, está diretamente ligado as diversas e diferentes formas de se pensar antes de tomar qualquer decisão. Para ele, tudo o que se refere ao pensamento reflexivo é uma forma de ação oriunda de um conhecimento prévio, ocasionado por um exame mental. Diante disso, os outros tipos de pensamentos são constituídos por uma sequência, assumindo ainda um caráter de consequência por tudo aquilo que é imaginado:

A reflexão não é simplesmente uma seqüencia, mas também uma conseqüência, uma sequência consecutiva onde as idéias compõem uma ação natural, e ao mesmo tempo, apoia-se naquilo que se refere. As partes sucessivas de um pensamento reflexivo são oriundos de uma, e subsiste às outras; não transitam inexplicavelmente (Dewey, 1959, p. $14)$.

\section{Percurso Metodológico}

O percurso metodológico, é o momento em que o investigador faz uso de técnicas apropriadas no intuito de realizar os registros adequados de todas as informações colhidas oriundas de seu trabalho, e posterior a isso, analisam com os critérios investigativos já previamente definidos. 
Desse modo, a escolha de um método que venha ao encontro da realidade ou da necessidade do pesquisador e de sua pesquisa é fundamental para o sucesso ou insucesso do trabalho a ser investigado.

A esse respeito, Minayo (1998) enfatiza que a forma metodológica deve envolver um conjunto de mecanismos com abordagens claras, concisas e que venha ao encontro da realidade dos sujeitos pesquisados.

A pesquisa qualitativa se sustenta pela forma metodológica de conceitos baseados em fatos oriundos de ideias e opiniões, e ainda da assimilação expressa dos sujeitos que relatam indutivamente ou interpretativamente aquilo que experienciaram antes, durante e depois da pesquisa, sempre interrelacionados com o problema levantado na referida pesquisa (Batista et al., 2009).

Cabe salientar que este trabalho também está atrelado à pesquisa-ação, por se tratar de uma análise envolvendo ações e reações diretas com os sujeitos envolvidos na pesquisa. Diante de todo esse envolvimento, foi possível coletar os dados sobre diferentes olhares, permitindo constatar que tanto o resultado da coleta, como também a forma como os pesquisados abordaram e suscitaram seus inúmeros relatos, problemas e soluções ao longo de toda a pesquisa, denomina-se por abordagem qualitativa, via pesquisa-ação.

Constata-se, portanto, que o presente trabalho é uma pesquisa descritiva pois envolveu técnicas de coleta de dados com determinada população ou sujeitos pesquisados.

\subsection{Análise de conteúdo em pesquisa qualitativa}

Com o intuito de se aproximar de uma pesquisa envolvendo problemas oriundos de qualquer natureza, sob o olhar de uma pesquisa qualitativa de cunho reflexivo, nota-se a existência de várias técnicas para a análise e interpretação dos dados necessários para construção de um trabalho sólido, embasado em evidências concretas, dando respaldo ao que está sendo proposto. Entre essas várias técnicas, destaca-se a Análise de Conteúdo, defendida pela pesquisadora Bardin (2016), e amplamente discutido pela ciência.

Segundo a autora supramencionada, objetiva-se, via Análise de Conteúdo, analisar o que foi dito ou interpretado por sujeitos durante a aplicação e investigação no momento da coleta e levantamento de dados, visando à construção de uma pesquisa.

Após a coleta dos dados, o pesquisador parte para uma etapa muito importante que é a análise e investigação do material levantado e coletado, seguindo sempre um processo detalhado no que tange às etapas defendidas por Bardin (2016), como: Pré-análise; Exploração do material; e Tratamento dos resultados.

A estrutura da referida proposta, foi construída da seguinte maneira: O Curso denominou-se de Metodologias Ativas na Formação de Professores de Física, seu tempo de duração foi de 12 de março de 2019 a 13 de novembro de 2019. O dia de execução deu-se às terças-feiras no período matutino, por ser o momento de realização da hora atividade dos professores de Física, pertencentes ao Núcleo Regional de Educação (NRE) do Município de Maringá.

No que se refere aos sujeitos da pesquisa, foram sete (7) participantes do curso, três (3) do sexo masculino e (4) do sexo feminino, no entanto dois (2) desses sujeitos trabalhavam no Núcleo Regional de Educação e não estavam em sala de aula, ou seja: não tinham turma para realização da referida implementação das atividades, participando assim apenas das etapas de estudos, planejamentos e discussões da proposta.

Em relação a descrição das atividades o mesmo deu-se da seguinte maneira: O curso foi dividido em três (3) módulos e cada módulo foi dividido em três (3) partes, a fim de que o professor vivenciasse uma experiência com as metodologias ativas em sua totalidade.

Os encontros aconteciam com um intervalo mínimo de 15 dias para que o professor participante da proposta tivesse tempo hábil para realização das leituras prévias, objetivando conhecer melhor a proposta com a qual estava trabalhando. Diante 
disso, toda a estrutura dos módulos fora definida conforme quadro abaixo:

Quadro 1: Etapa descritiva dos módulos.

\begin{tabular}{|l|l|}
\hline \multicolumn{2}{|l|}{ MÓDULOS } \\
\hline PARTE 1 & DESCRIÇÃO \\
\hline $\begin{array}{l}\text { Os professores participantes do curso vivenciam uma atividade prática preparada com a fundamentação teórica do módulo. Os } \\
\text { mesmos, devem realizar a atividade como se fossem alunos, a fim de conhecer o passo a passo. Em seguida, é feito uma discussão } \\
\text { sobre os fundamentos teóricos, para que os professores possam compreender a atividade que haviam acabado de realizar. Nesta aula } \\
\text { também foi disponibilizado para os professores participantes leituras complementares sobre o tema estudado. }\end{array}$
\end{tabular}

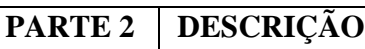

Na segunda parte do módulo os professores participantes do curso deveriam planejar uma atividade utilizando a metodologia ativa estudada para implementar em sua sala de aula. Nesta etapa eles devem pesquisar, trabalhar em grupos menores, com no máximo três pessoas, estruturando suas propostas. Os docentes responsáveis pelo curso de metodologias ativas auxiliavam os grupos sempre que necessário. Nesse intervalo de tempo o professor participante tinha dois encontros presenciais para terminar o planejamento de sua proposta, no entanto tínhamos um grupo colaborativo no "WhatsApp" que poderiam entrar em contato em qualquer tempo. Após a atividade pronta o professor deveria implementá-la em sua aula, na turma escolhida por ele, não foi pré-determinado o conteúdo, a turma ou a quantidade de aulas, isso ficou a critério de cada professor.

\section{PARTE 3 DESCRIÇÃO}

Na terceira parte, os professores relataram com detalhes suas experiências com a implementação da proposta.

Fonte: Autores (2021).

Quadro 2: Estrutura do curso de metodologias ativas na formação de professores de Física.

\begin{tabular}{|c|c|}
\hline \multicolumn{2}{|c|}{ MÓDULO 1: APRENDIZAGEM BASEADA EM PROBLEMAS (PBL) } \\
\hline PARTE 1 & DESCRIÇÃO \\
\hline $12 / 03$ & $\begin{array}{ll}\checkmark & \text { Os professores participantes do curso vivenciaram uma atividade PBL na prática; } \\
\checkmark & \text { Discussão sobre os fundamentos teóricos da PBL; } \\
\checkmark & \text { Leituras complementares sobre o tema estudado. }\end{array}$ \\
\hline PARTE 2 & DESCRIÇÃO \\
\hline $02 / 04$ a 23/04 & $\begin{array}{ll}\checkmark & \text { Elaboração da proposta de uma atividade PBL; } \\
\checkmark & \text { Implementação da proposta na turma escolhida. }\end{array}$ \\
\hline PARTE 3 & DESCRIÇÃO \\
\hline $14 / 05$ & $\begin{array}{ll}\checkmark & \text { Relato da experiência do professor com a implementação. }\end{array}$ \\
\hline \multicolumn{2}{|c|}{ MÓDULO 2: ATIVIDADE EXPERIMENTAL INVESTIGATIVA } \\
\hline PARTE 1 & DESCRIÇÃOO \\
\hline $11 / 06$ & $\begin{array}{ll}\checkmark & \text { Os professores participantes do curso vivenciaram uma atividade experimental investigativa na prática; } \\
\checkmark & \text { Discussão sobre os fundamentos teóricos do ensino por investigação; } \\
\checkmark & \text { Leituras complementares sobre o tema estudado. }\end{array}$ \\
\hline PARTE 2 & DESCRIÇÃO \\
\hline $25 / 06$ a $30 / 07$ & $\begin{array}{ll}\checkmark & \text { Elaboração da proposta de uma atividade investigativa; } \\
\checkmark & \text { Implementação da proposta na turma escolhida. }\end{array}$ \\
\hline PARTE 3 & DESCRIÇÃO \\
\hline $20 / 08$ & $\begin{array}{ll}\checkmark & \text { Relato da experiência do professor com a implementação. }\end{array}$ \\
\hline \multicolumn{2}{|c|}{ MÓDULO 3: SALA DE AULA INVERTIDA } \\
\hline PARTE 1 & DESCRIÇÃO \\
\hline $10 / 09$ & $\begin{array}{ll}\checkmark & \text { Os professores participantes do curso vivenciaram uma atividade de sala de aula invertida; } \\
\checkmark & \text { Discussão sobre os fundamentos teóricos da sala de aula invertida; } \\
\checkmark & \text { Leituras complementares sobre o tema estudado. }\end{array}$ \\
\hline PARTE 2 & DESCRIÇÃO \\
\hline $01 / 10$ a $22 / 10$ & $\begin{array}{ll}\checkmark & \text { Elaboração da proposta de sala de aula invertida; } \\
\checkmark & \text { Implementação da proposta na turma escolhida. }\end{array}$ \\
\hline PARTE 3 & DESCRIÇÃO \\
\hline $12 / 11$ & $\checkmark \quad$ Relato da experiência do professor com a implementação. \\
\hline
\end{tabular}

Fonte: Autores (2021). 
Com tudo, tais discussões não se encerram com a finalização deste estudo, mas ao contrário, entende-se que o cerne desta temática está diretamente ligado a três importantes fases vivenciadas no cotidiano dos professores analisado ao longo de todo curso de formação continuada, os diferentes discursos e comportamentos dos professores diante dos avanços com a aplicação das atividades em sala de aula para os seus respectivos alunos. Tais práticas, levou-se a divisão de três (3) importantes etapas, denominadas de:

Discurso da queixa: evidencia-se os professores muito resistentes em relação a proposta do ensino via metodologias ativas, os mesmos demonstram preocupação em relação ao cumprimento da proposta prevista para o curso de formação continuada. Diante de tais insatisfações a atitude dos mesmos então, é a de queixar-se com relação à falta de recursos tecnológicos e inovações, de alunos não participativos nas aulas, da falta de interesse nas atividades por parte dos mesmos, o que explicariam o insucesso no processo de aprendizagem, ou seja, fica claro que para alguns professores o fracasso escolar está condicionado à incompetência dos alunos, de suas famílias, às péssimas condições de trabalho e à crescente perda da autoridade do professor em sala de aula.

Segundo alguns pesquisadores (Pacca \& Villani, 2000; Barros et al., 2006), diante de um certo nível de conhecimento o professor ministra suas aulas sem posicionar-se mantendo uma atitude defensiva, levantando pontos negativos, remetendo todos os problemas encontrados em sala de aula sempre aos outros, nunca trazendo para si.

Segundo a proposta de Perrenoud (1999), para um desempenho de qualidade, o profissional educador, cria, desenvolve, constrói diferentes habilidades e competências que lhe permitem agir eficazmente em determinados tipos de situação, apoiado em conhecimento, mas sem limitar-se a eles.

Discurso do conhecimento metodológico: tal prática está diretamente ligado ao problema da falta de motivação dos alunos no que tange o cumprimento das atividades em sala de aula. O professor apresenta possibilidades de aulas inovadoras fazendo uso de recursos tecnológicos e estratégias de ensino, com intuito de alcançar um alto nível de satisfação dos alunos no que se refere a aprendizagem. O professor parece procurar um método a prova de suas próprias falhas, que funcione pelas suas qualidades intrínsecas, uma "nova maneira de ensinar". Basta achar os elementos adequados e o ensino torna-se uma tarefa fácil e agradável.

Discurso do conhecimento reflexivo: relacionado à adesão ao conhecimento teórico e prático sobre a aprendizagem em ciências, enfatizando a necessidade de participação ativa do aluno em seu domínio de conhecimento por autonomia. Focaliza a atividade reflexiva do professor, para que ele possa acompanhar a evolução da aprendizagem de seus alunos.

\section{Resultados e Discussão}

Neste trabalho, apresenta-se uma análise e interpretação referente a atuação dos (5) professores, aqui representados pelos "codinomes" P1, P2, P3, P4 e P5, participantes do curso de formação continuada em metodologias ativas do início até o fim do projeto, com uma evolução bastante surpreendente em suas falas como também em suas práticas pedagógicas.

A tomada de dados foi realizada durante os encontros onde todos os depoimentos dos professores foram gravados em áudios e posteriormente transcritos na integra, para as devidas análises.

Ao analisar tais evoluções nota-se mudanças de pensamentos e posições subjetivas por parte desses professores no que tange o uso de metodologias ativas em suas práticas docentes.

Etapa 1: Nessa primeira etapa denominada por Discurso de Queixa, analisa-se antes da aplicação das atividades propriamente dita, todo um discurso prévio dos professores em relação as suas práticas pedagógicas atuais e existentes em sala de aula. Notase então, vários e diferentes discursos sobre a desmotivação dos mesmos em ensinar e dos alunos em aprender, o despreparo e/ou insegurança de muitos professores em fazerem uso de recursos midiáticos, entre outros.

Diante dessa realidade, Abreu (2009), afirma que: 
As tecnologias são muito mais do que artefatos e aplicativos: são ambientes de vida. Integram cultura e competências digitais: um mundo em que tudo se mistura, em que tudo está sempre ao nosso alcance, disponível para aprender, criar e compartilhar (Abreu, 2009, p. 75).

Ainda segundo o autor, a BNCC destaca a importância da compreensão, utilização e criação das tecnologias digitais de forma crítica, significativa, reflexiva e ética nas diversas práticas sociais (incluindo as escolares), para se comunicar, acessar e disseminar informações, produzir conhecimentos, resolver problemas e exercer protagonismo e autoria na vida pessoal e coletiva (Silva, 2020, p. 75).

Caso do Professor P1: O professor não acredita na eficácia dessa prática docente, recusa o papel de responsabilidade diante do despreparo, transferindo-o para um sentimento de desinteresse por parte dos alunos, ou seja, só realizam algo mediante o alcance de notas. Essa afirmativa torna-se ainda mais claro e evidente conforme afirmação do professor que segue abaixo:

"Então vamos fazer uma coisa diferente, pelo menos nesse início, vocês vão dar uma nota a eles, pelo menos assim talvez eles façam algo, caso contrário não vão realizar a atividade” (P1).

Caso do Professor P2: Aqui evidencia-se sentimentos de incertezas e falta de credibilidade por parte do referido professor (P2), no que se refere aos interesses dos alunos pela aprendizagem, na fala evidencia-se a sua preocupação pelo método avaliativo e não pelo processo de aprendizagem, conforme afirmações que seguem abaixo:

"Acho que hoje, numa sala de trinta e cinco alunos, se vai encontrar uns quatro, cinco interessados no que você tá ensinando, sério, se você me cobrar uns cinco tem uma nota boa, e ainda teremos problemas futuros com os pais desses alunos, caso algum reprove" (P2).

Na sequência, permanece o sentimento de descrédito por parte do professor ao se referir aos seus alunos em relação ao alcance de notas, como também sua preocupação em relação à família dos mesmos.

"Se for recuperação ainda é maior, por que a gente sabe que ele vai depender daquela nota, e ainda teremos alguém da família desse aluno nos procurando, porque o estímulo maior hoje é a nota, se não nem tem o interesse no aprendizado em si, é muito difícil né, a nossa realidade educacional hoje do ensino médio é essa" (P2).

Nesse momento aparece o sentimento de dúvidas e/ou angústia por parte do professor em relação a forma de avaliar os alunos, ao falar de suas dificuldades, o professor foi capaz de tomar consciência dos problemas relacionados a forma de avaliar cada conteúdo dado em suas aulas, conforme segue:

"Uma coisa que eu aprendi é a refaç̧ão da prova e às vezes eu escrevo assim: Valendo 1 ponto no caderno pra refazer e às vezes eu escrevo assim: valor: conhecimento, quando eu coloco ali um ponto todo mundo faz, quando é conhecimento no caderno alguns fazem outros não" (P2).

Caso do Professor P3: As afirmações do referido professor, deixa claro sua preocupação em relação a aquisição de conhecimentos dos alunos tendo acesso à internet. Em seu discurso aparece essa preocupação do aluno não procurar avançar no conhecimento e somente buscar os resultados prontos no acesso rápido as redes sociais e a internet, conforme segue: 
"Pensa numa coisa, o aluno até pode ter visto o experimento a cânone do texto, só que ele tem que explicar depois qual o entendimento que ele teve diante daquele conteúdo, ele pode copiar do experimento, mas ele tem que ter executado ele, depois ele tem que explicar o que ele entendeu, se ele não fazer nenhuma dessas duas coisas, ele não vai ter conhecimento nenhum, ele pode ter isso facilmente na internet, mas isso não vai mudar o conhecimento dele em nada. A internet está ali, ela é um recurso pra eu dar o meu jeito de entender as minhas coisas, mas não pra tudo" (P3).

Caso do Professor P4: Durante a fala do professor, o mesmo se demonstra bastante insatisfeito com as várias formas e maneiras de avaliar todo processo de aprendizagem de seus alunos em sala de aula, conforme segue:

"Já tentei de tudo com os meus alunos, e eles não demonstram interesse algum por aprender. A sala de aula já não os atrai mais" (P4).

Caso do Professor P5: Já para esse professor, durante sua fala evidenciou-se uma grande insatisfação do mesmo pelo sistema pedagógico da escola, onde para todas as atividades que são propostas tudo torna-se ainda mais difícil quando se tem que cumprir além das aulas, uma vasta entrega de materiais didáticos e planos de aulas para equipe pedagógica, conforme segue relato:

\begin{abstract}
"Você tem que entregar por escrito pra pedagoga as atividades que você vai fazer, o que você vai fazer, a nota que você vai dar, anexado o plano de aula e entregar pra eles, então isso aí já amarra nesse esquema, aí o pedagogo chama o aluno pra conversar: Ah, mas o professor aquele dia deu aquela matéria fora do planejamento, você entendeu como é a coisa? Então eles ficam assim, sem interesse do aprendizado em si, em buscar o conhecimento, aí fica uma situação assim, que tudo amarra, plenamente você é amarrado" (P5).
\end{abstract}

Etapa 2: Nessa segunda etapa denominada por Discurso do Conhecimento Metodológico, evidencia-se as ações docentes que estão diretamente ligadas aos problemas oriundos em relação a motivação dos alunos em estar cumprindo as atividades de sala de aula, nota-se a insatisfação e frustração dos professores em não estar atendendo satisfatoriamente seus alunos e consequentemente a aprendizagem não acontecendo por conta de uma aula repetidas vezes tradicionalista demais.

Caso do Professor P1: Com o passar dos meses, e diante das experiências adquiridas ao longo do curso de formação continuada, esse professor passou a sinalizar um grande interesse pelo que lhe era apresentado, e em sua fala, já fica claro e evidente a sua saída da inércia inicial sempre respaldado por um uma série de queixas e obstáculos, para algo que é possível de ser realizado. Ele acaba interessando-se mais pelo conteúdo a ser transmitido, e passa a descobrir lacunas na base teórica adquirido ao longo de sua formação acadêmica, reconhecendo as deficiências de conteúdo decorrentes da sua precária formação no magistério, reconhecendo a necessidade da capacitação permanente, conforme segue descrição a seguir:

\footnotetext{
"Em minha aula irei propor a seguinte situação: Qual associação as cargas se dividem num circuito enquanto a tensão impulsiona? Como a tensão se divide enquanto a corrente é conduzida? Quero que eles provem se é verdadeiro ou falso, depois... Agora embaixo, em paralelo as lâmpadas do brilho é mais intensa e em série brilha menos. É verdade ou mentira? Quais seriam as vantagens e desvantagens da associação em série e em paralelo? Por que usar aspas na palavra "série"? Relacione estas associações com as leis de Pearl, acredito que dê certo" (P1).
} 
Caso do Professor P2: O trecho abaixo revela uma evolução por parte do professor, bem como um desejo em repetir um conteúdo aplicado anteriormente aos alunos, e a sua necessidade em verificar se o aprendizado adquirido anteriormente foi eficaz ou não.

"Irei propor aos meus alunos circuitos elétricos, eles já tinham estudado, assim, experimentado que era uma maravilha... Vamos mexer aqui e ver o que acontece, acredito que dessa forma a aprendizagem aconteça. A idéia, da proposta eles já conhecem, mas eles retornarão agora pensando no sentido "como" né? Uma lâmpada continua acesa e a outra apaga ou porque apagam as duas? Penso que dará certo” (P2).

Caso do Professor P3: Também se evidenciou no discurso que segue abaixo a fase de autonomia por parte dos alunos, onde os mesmos passaram pela fase da dúvida, ao sanarem tais dúvidas e incertezas, decidiram trocar de projeto e consequentemente sua forma metodológica. Mesmo a atividade não atendendo a demanda em sua totalidade, o professor sente-se satisfeito por observar que os alunos começam a encaminhar todo percurso para realização das atividades que lhes são confiadas, conforme segue:

"É, quando estava na fase de orientação, passou as instruções e eles começaram a pensar no que iriam fazer e vieram tirar dúvidas e, eles mudaram de projeto, "Professor essa canaleta aqui como é?" Estava querendo que desse certo, aí mudou o projeto, né. O importante é eles discutir e repensar. E percebi que eles montaram só em paralelo, mas quem tira a tensão e a corrente é uma daquela, quando tem, como é que eles falam que vai acontecer? O tico e o teco. Eles não trouxeram em série, trouxeram somente em paralelo, mas a aula foi excelente!”(P3).

Caso do Professor P4: Nesse caso, explicita-se a preocupação do professor em apresentar aos alunos um conteúdo onde todos possam desempenhar muito bem o seu papel com maestria. No entanto, deve-se observar o fato de que esse professor passa a se apropriar da metodologia de ensino como se fosse capaz de estabelecer um método milagroso para os diversos dilemas enfrentados por ele no seu dia a dia.

“Eu irei propor uma argumentação em três apresentações. E observar também a motivação deles, mesmo que é um circuito que eles precisarão fazer, em outra ocasião eles se mostraram bastante empenhados, é quase como um seminário para apresentar que acabam questionando, né. Mas "ó", a etapa de pergunta ficou boa, agora é a apresentação. E, para três equipes, equipe $A, B$ e $C$, eles também terão que investigar ali um pouquinho sobre medidores em associação usando multímetro interim, é isso que falta concluir, essas medidas. A equipe "A", eles farão dois circuitos, que foi esse daqui que a gente já fez e em paralelo que é esse daqui. Agora então faz o em série, aí quando chegar aqui na série explicarei em paralelo" (P4).

Caso do Professor P5: Com os vários discursos desse professor que segue abaixo, evidencia-se que ele começa a dar importância ao aprendizado do aluno, ou seja, expressou uma preocupação maior com uma produção mais autônoma dos mesmos, em um de nossos encontros de formação continuada, ele relata como foi a sua nova experiência, e neste nesse discurso nota-se a positividade do mesmo, afirmando que “foi muito bom”, “que a turma participou”, porém, o mesmo acabou se dando conta que tem várias falhas em seu conteúdo teórico, com isso é possível inferir que ele venceu a barreira inicial, da insegurança, pois os alunos deram o retorno esperado, e o professor começa a fazer planos para as próximas aulas, por fim, se 
dá conta de que sua formação foi insuficiente, com isso ele acaba sendo capturado pelo discurso do conhecimento científico, nesse discurso a escola deve transmitir conhecimento e o papel do professor é tornar-se fonte dele.

"Estou pensando um utilizar com meus alunos para que eles entendam bem certas aplicações em impressão 3D, já vê necessidade de criar né, mesmo não tendo a impressão 3D, ele já vê a possibilidade de algo ser criado" (P5).

Etapa 3: Na terceira etapa denominada por Discurso do Conhecimento Reflexivo, a mesma está diretamente ligado à adesão por parte dos professores a todo conhecimento teórico e prático adquirido no dia a dia no que tange a aprendizagem de conhecimento por autonomia.

Caso do Professor P1: No decorrer do curso, o professor demonstra cada vez mais interesses, tanto que ele foi um dos primeiros professores a queixar-se na fase inicial do curso, mas também foi o primeiro a aplicar tais atividades em sala de aula. Durante a aplicação com seus alunos, o mesmo percebeu quão deficitária foi sua formação, em seus discursos iniciais nota-se algumas dificuldades e através delas o mesmo conscientiza-se de alguns problemas relacionados com seu conteúdo. Só então começa a buscar pelo conhecimento, privilegiando o conhecimento científico, fica claro que esse professor torna-se imerso pelas práticas do conhecimento científico, este consiste em que a escola deve transmitir todo conhecimento e o papel do professor é tornar-se fonte dele.

"Estou cada dia mais interessado e disposto a continuar fazendo uso dessas práticas para melhorar meu trabalho docente, no início desses nossos encontros eu não acreditava na eficácia dessa forma metodológica de ensinar, mas vi que me enganei, porém, vi também que minha formação acadêmica deixou a desejar em vários aspectos, hoje vejo que o conhecimento científico está presente em todas as áreas do conhecimento, assim como falou o nosso colega" $(P 1)$.

Caso do Professor P2: Na fala a seguir, nota-se a tomada de consciência por parte deste professor ao afirmar que os objetivos foram alcançados e os conhecimentos tornaram-se eficazes via práticas pedagógicas permeados pelas metodologias ativas:

"Eu achei muito interessante quando meus alunos foram abordados por práticas pedagógicas até então desconhecidas por eles, hoje eu vejo que assim é que constrói o conhecimento científico, não penso mais em parar" (P2).

Caso do Professor P3: Na fala que segue, o professor se convence de que o uso das metodologias ativas torna as aulas mais prazerosas, com uma aprendizagem mais eficaz, e consequentemente o conhecimento científico mais presente no dia a dia tanto do professor quanto dos alunos.

"É, mas são perguntas sobre os cursos, eles estão perguntando especificamente sobre os cursos, eu tenho falado muito do curso de física, tenho feito muito propaganda desse especificamente, tenho falado sobre metodologias né, as metodologias, posso chamar de metodologias ativas? Mas a gente fala, fala muito, e daí até uma professora de Geografia ela falou nossa, a gente precisa levar isso paras outras né, outras. Esses cursos eles têm que ser feitos, ampliados para outras áreas né, infelizmente a gente fica com turmas reduzidas né, porque são cursos onde precisa se trabalhar muito né, mas são cursos que realmente pra mim, né no meu caso eu tô vendo que não só pra mim, mas 
pra todo mundo, estão causando um acréscimo, então a gente começa ver outras maneiras e mais gratificantes de se trabalhar" (P3).

“Que a gente está vendo por que eu, assim nós do ensino médio, eu acho complicado, assim no meu colégio eu acabei tendo que ceder né a essa coisa de se avaliar caderno de aluno eu acho que, por que todo ensino médio, todos os professores sozinhos, então vamos cuidar, olhar a atividade e tal e fazia então eu vi que ninguém fazia atividade nenhuma, dois alunos faziam né e eu tive que começar dar um ponto no bimestre, dois pontos no bimestre pra quem fazia todas as atividades no caderno. Então é algo que se o colégio não tivesse essa alternativa, talvez não precisasse a gente fazer isso, se a gente realmente motivasse o fato de que ah, tudo tem a ver com o conhecimento. Igual eu faço hoje em dia, hoje em dia eu faço assim: é surpresa, isso no ensino fundamental e no médio, matemática ou física, ou seja, dá pra valer nota?" (P3).

Caso do Professor P4: Nos relatos que seguem, evidencia-se uma possível mudança de postura do professor, ficando claro que o importante para ele, neste momento, é a participação ativa dos alunos no processo ensino-aprendizagem, ou seja, o mesmo começou a refletir sobre a sua prática pedagógica, deixou de lado os problemas que envolviam o processo, dando uma atenção maior para o aprendizado dos alunos.

\footnotetext{
"Mas eu achei bem interessante assim é, é treinar essas habilidades nos alunos, justificar o medo que eles têm de mexer com eletricidade. Então eu creio que competência e habilidade em circuito elétrico com corrente contínua né, pensando hoje” (P4).

"Perderam esse medo, né. Digamos aí que é o segundo ou terceiro experimento que eles já fizeram de eletricidade aqui, eles gostaram muito e querem repetir com outros experimentos" (P4).
}

Caso do Professor P5: Já nos encontros finais observa-se nas falas do professor, que, o discurso que prevalece é o do conhecimento metodológico, mesmo em um de seus depoimentos, colocando a importância de fazer com que o aluno aprenda, evidenciando-se um discurso do conhecimento reflexivo.

“O grupo cinco, eles fizeram um, deixa eu ver, até tirei a foto aqui, a menina fez no quadro, é, primeiro, ela falou, ela tentou argumentar o seguinte, ela tentou fazer um esquema, essa figurinha aqui em cima representa a água, né, essa outra pessoinha aqui é o calor, não é isso? Então, o papel perdão...esse daqui é o papel, e esse papel, ele tá sendo, digamos, tá indo pro desfiladeiro, se o calor conseguir vencer esse papel, o papel cai num local onde ele vai pegar fogo, então a água tá ajudando... Ela tentou, ela falou assim: A nossa equipe, entendeu que o processo aí de a água estar interferindo no processo de o papel não pegar fogo funciona mais ou menos assim... Eu achei interessante que ela comentou sobre capacidade térmica, colocou a fórmula ali no quadro e associou depois com calor específico, daí ela, daí a equipe dela entendeu... tem uma questão mencionando o experimento ali embaixo, mas primeiro pra introduzir o assunto, falei...ah vou tirar foto né, por que eu achei interessante, que eles introduziram né, usando o ,colocando uma representação em pessoas ali né, é argumentaram a respeito de catáse concluída, mostrando o calor que é necessário para... Ata, na questão do experimento eles não foram muito assertivos, por que daí, apesar daqui, eles interpretarem o processo, eles usaram o conceito de calor, que o calor é usado pra transformar e moldar substâncias como vidro, então daí não ficou muito em cima do experimento lá, que eles tinham acabado de assistir um filme francês ali que isso acontece, no filme mostra a francesa lá, em que aparecia muito o calor, o vidro sendo derretido da evolução, então isso ficou muito na cabeça deles. Bem, é essa sexta equipe aqui, calor, saco de dormir, 
ela fala sobre o fato de usarem sacos de dormir né, como ideia de revestir internamente com telas de lençol metalizado com a intenção de você fazer uma também, uma... manter né tentar preservar né um pouco do reflexo do calor interno por irradiação, então é... transferências da irradiação... não mencionaram a relação com o experimento. Então tiveram algumas equipes que tiveram conexão com o experimento e algumas, mencionaram, divagaram por outras da condução e irradiação e processo de tal" (P5).

\section{Considerações Finais}

A educação quando imposta, comporta-se apenas como uma mola propulsora das desigualdades e insatisfações tanto dos alunos quanto dos professores, ocultando a realidade dos fatos, tornando-se apenas uma questão técnica sustentada pelos princípios da ciência totalmente imparcial.

Ao contrário disso, o conhecimento por sua vez, deve possuir comprometimento e autonomia, no sentido de que os alunos e professores são igualmente responsáveis pela aquisição do conhecimento, onde o saber não poderá jamais ser imposto e sim construído e partilhado. É uma tarefa de troca entre professor e aluno, não um "faz de conta" da educação, onde o professor dissimula o conhecimento e o aluno a aprendizagem.

O presente artigo evidenciou por meio de um curso de formação continuada diferentes posturas de professores no cotidiano de suas aulas, objetivou a promoção de um trabalho coletivo entre esse grupo, de tal modo que os mesmos refletiram sobre suas práticas pedagógicas, realizando importantes reflexões no que tange sua ação docente e a sua relação com os saberes profissionais. Permitindo ainda uma vivência de todas as importantes etapas para construção do conhecimento, através da realização de atividades propostas pelo curso de formação continuada, sempre com intuito de provocar uma reflexão partindo deles no que diz respeito aos elementos que caracterizam o conhecimento científico e a ação pedagógica em sala de aula.

Com isso, na etapa um, evidenciou-se professores presos a um discurso de queixas, onde os mesmos ministravam suas aulas sem nenhum tipo de posicionamento, sempre com atitudes defensivas, ficando claro os impasses e repetições marcados por um conjunto de aulas repetitivas, revelando com isso a impotência, fracasso e frustrações diante de alunos que não se sentem motivados em participar das atividades propostas. Diante de tais fatos os professores recusavam o papel de responsabilidade perante o fracasso, transferindo para a família todo e qualquer tipo de responsabilidade perante a não aprendizagem de seus filhos.

Com o avanço do curso de formação continuada, na etapa dois, ao se depararem com as diferentes formas de planejamento didático pedagógico via metodologias ativas, o referido grupo de professores, passou a demonstrar interesses pela proposta inicial do curso. Na fala de alguns evidenciou-se a saída da inércia, sempre acompanhado por um discurso pautado por muitas queixas, passando a se interessarem mais pelos conteúdos abordados, e descobrindo várias lacunas em suas formas metodológicas de transmitir o conhecimento, reconhecendo suas deficiências de conteúdo oriundos de uma formação inicial muito instável durante o magistério, confessando a necessidade de constantes atualizações.

Já na etapa três, ficou claro o desejo do grupo de professores em aprender, bem como o de buscar sempre pelo conhecimento científico. Evidenciou-se ainda que após a tomada de consciência das muitas dificuldades de conteúdos ligados a formação de magistério, imediatamente os professores passaram a preocupar-se mais com a forma de promover a aprendizagem dos alunos do que unicamente com a transmissão de conteúdos científicos. Diante de tais fatos, constata-se que esse grupo de professores passou para a apropriação das muitas formas metodológicas de ensino.

Com a finalização do curso de formação continuada, evidenciou-se ainda em seus diferentes discursos a importância da aprendizagem do aluno, ou seja, uma preocupação maior com uma produção mais autônoma dos mesmos. 
Acredita-se que o objetivo foi alcançado, pois a partir do momento que os professores conseguiram superar os problemas com os conteúdos e com a metodologia de ensino, eles refletiram muito sobre suas ações e suas práticas, alguns até realizando críticas às suas aulas tradicionais tão habituais.

Em relação aos trabalhos futuros, há o desejo de se construir aulas de metodologias ativas, permeadas pela gamificação, fazendo com isto que o nível de motivação dos alunos por estarem em uma sala de aula, aprendendo e investigando novos saberes docentes via jogos, aumente de uma forma considerável.

Considera-se que essas sejam importantes decisões para uma postura do profissional da educação. Fundamentar-se na teoria, refletir sempre sobre suas práticas, onde aplicar e como aplicar seus conhecimentos, libertar-se das ações meramente burocráticas, construir iniciativas em função dos alunos. Em suma, exercer a profissão docente é escolher uma forma própria de ser educador, sempre adequada a realidade do momento, sempre enfrentando, qualitativamente, os obstáculos presentes na prática cotidiana.

\section{Referências}

Abreu, J. R. P. D. (2009). Contexto atual do ensino médico: metodologias tradicionais e ativas: necessidades pedagógicas dos professores e da estrutura das escolas. 2011. 105 f. Dissertação (Programa de Pós-Graduação em Ciências da Saúde) - Universidade Federal do Rio Grande do Sul. Porto Alegre, 2009.

Alarcão, I. (2007) Professores Reflexivos em uma Escola Reflexiva. (5a ed.), Cortez.

Azevedo, M. C. P. S. (2004). Ensino por investigação: problematizando as atividades em sala de aula. Ensino de ciências: unindo a pesquisa e a prática. São Paulo: Pioneira Thomson Learning, 3, 19-33.

Bardin, L. (2016) Análise de Conteúdo. Edição 70.

Barrell, J. (2007) Problem-Based Learning. An Inquiry Approach. Thousand Oaks: Corwin Press.

Bassalobre, J. N. (2013). Ética, responsabilidade social e formação de educadores. Educação em Revista, 29, 311-317.

Barros, M. A., Arruda, S. M. Laburú, C. E., Batista, M. C., \& Silva, A. I. Entre a queixa e a reflexão: a promoção de mudanças no discurso de um grupo de professoras de ciências do ensino fundamental. Rev. Ensaio. 08(02), 132-145.

Batista, M. C., Fusinato, P. A., \& Blini, R. B. (2009). Reflexões sobre a importância da experimentação no ensino de Física. Acta Scientiarum. Human and Social Sciences, 31(1), 43-49.

Bauman, Z. (2009). Os desafios da educação: aprender a caminhar sobre areias movediças. Cadernos de Pesquisa, 39(137), 661-684.

Berbel, N. A. N. (2011). As metodologias ativas e a promoção da autonomia de estudantes. Semina: Ciências sociais e humanas, 32(1), 25-40.

Borges, T. S., \& Alencar, G. (2014). Metodologias ativas na promoção da formação crítica do estudante: o uso das metodologias ativas como recurso didático na formação crítica do estudante do ensino superior. Cairu em revista, 3(4), 119-143.

Brito, A. E. (2006). Formar professores: rediscutindo o trabalho e os saberes docentes. Formação de professores e práticas docentes: olhares contemporâneos. Belo Horizonte: Autêntica, 41-53.

Carvalho, C. J. (2009). O Ensino e a Aprendizagem das Ciências Naturais através da Aprendizagem Baseada na Resolução de Problemas: um estudo com alunos de $9^{\circ}$ ano, centrado no tema Sistema Digestivo (Doctoral dissertation).

Carvalho, A. M. P. D., \& Gil-Pérez, D. (2011). Formação de professores de ciências: tendências e inovações. Cortez.

Dewey, J. (1959). Como pensamos: como se relaciona o pensamento reflexivo com o processo educativo: uma reexposição. 1959. Companhia Editora Nacional.

Minayo, M. C. S. O desafio do conhecimento: pesquisa qualitativa em ensino., 1998.

Nesi, E. R., Batista, M. C., \& Deimling, N. N. M. A formação continuada de professores de física no estado do paraná: um olhar a partir do mestrado nacional profissional em ensino de física (MNPEF). Revista Valore, Volta Redonda, 6 (Edição Especial): 510-522, 2021.

Nóvoa, A. (1992). Formação de professores e profissão docente. In: Os professores e a sua formação. Nóvoa (org.), Lisboa, Dom Quixote, 1992.

Pacca, J. L. A., \& Villani, A. (2000). La competencia dialógica del profesor de ciencias en Brasil. Enseñanza de las ciencias: revista de investigación y experiencias didácticas, $95-104$.

Pereira, Z. T. G., \& da Silva, D. Q. (2018). Metodologia ativa: Sala de aula invertida e suas práticas na educação básica. REICE: Revista Iberoamericana sobre Calidad, Eficacia y Cambio en Educación, 16(4), 63-78. 
Research, Society and Development, v. 10, n. 12, e12101220014, 2021

(CC BY 4.0) | ISSN 2525-3409 | DOI: http://dx.doi.org/10.33448/rsd-v10i12.20014

Pereira, R. (2012). Método ativo: técnicas de problematização da realidade aplicada à Educação Básica e ao Ensino Superior. VI Colóquio internacional. Educação e Contemporaneidade. São Cristóvão, SE, 20.

Perrenoud, P. (1999). Construir as competências desde a escola, trad. Bruno Charles Magne. Artmed.

Silva, A. C. (2020). Ensino de Ciências por investigação: um levantamento em periódicos da área. Revista de Ensino de Ciências e Matemática, 11(6), 306329.

Silva, D. O, Mourão, M. F., Sales, G. L., \& Silva, B. D. Metodologias ativas de aprendizagem: relato de experiência em uma oficina de formação continuada de professores de ciências. Revista Eletrônica Científica Ensino Interdisciplinar, 4(12), 502-516.

Silveira, R. M. C. F., \& Fabri, F. (2020). Formação continuada para professores dos anos iniciais: enfoque ciência, tecnologia, sociedade (cts) no ensino de ciências. REnCiMa, São Paulo, 11(4), 169-190.

Tardif, M. (2000). Saberes profissionais dos professores e conhecimentos universitários. Revista brasileira de Educação, 13(5), 5-24. 